NASA Technical Memorandum 103165

AIAA-90-2240

\title{
Combustor Design and Analysis Using the Rocket Combustor Interactive Design (ROCCID) Methodology
}

Mark D. Klem

Lewis Research Center

Cleveland, Ohio

Jerry L. Pieper and Richard E. Walker

Aerojet Techsystems

Sacramento, California

Prepared for the

26th Joint Propulsion Conference

cosponsored by the AIAA, SAE, ASME, and ASEE

Orlando, Florida, July 16-18, 1990

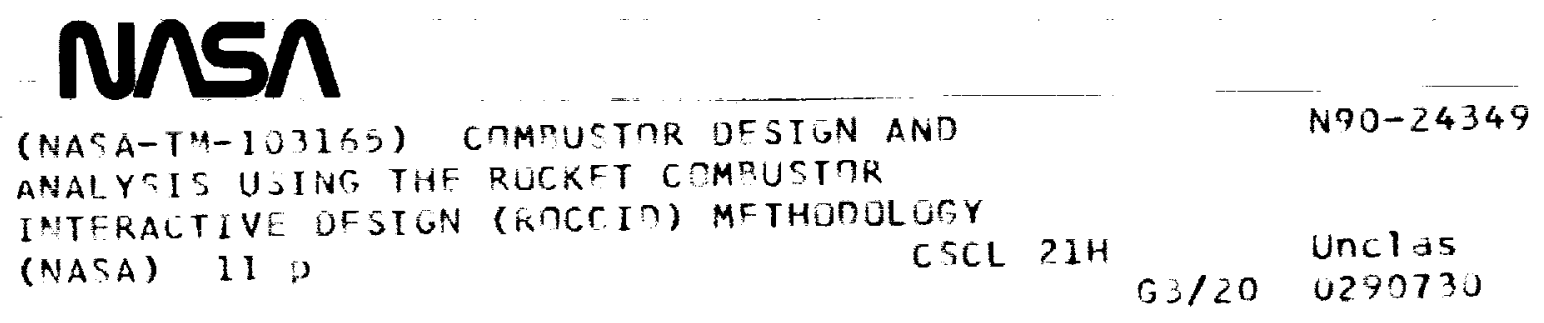


COMBUSTOR DESIGN AND ANALYSIS USING THE ROCKET COMBUSTOR

INTERACTIVE DESICN (ROCCID) METHODOLOGY

\author{
Mark D. Klem" \\ NASA Lewis Research Center \\ Cleveland, Ohio 44135 \\ Jerry L. Pieper" and Richard E. Walker" \\ Aerojet Techsystems \\ Sacramento, California 95813
}

\section{Abstract}

The Rocket Combustor Interactive Design (ROCCID) Methodology is a newly developed, interactive computer code for the design and analysis of a liquid propellant rocket combustion chamber. The application of ROCCID to design a liquid rocket combustion chamber is illustrated. Designs for a 50,000 lbf thrust and 1250 psi chamber pressure conbustor using Liquid 0xygen (LOX)/RP-1 propellants are developed and evaluated. Tradeof $f$ setween key design parameters affecting combustor performance and stability are examined. Predicted performance and combustion stability margin for these designs are provided as a function of the combustor operating nixture ratio and chamber pressure.

\section{Introduction}

An analytical design methodology to perform design tradeoffs leading to a high performing and stable combustion device for liquid propellant rocket engines has been recently developed. 1 This design methodology, ROCket Combustor Interactive Design (ROCCID), contains previously developed and available analysis models for characterizing the effects of critical design and operating parameters on the performance and combustion/stability of liquid propellant combustors. Recently, ROCCID has been released to a limited number of users in a "Beta Test" (selected users debug and evaluate sof $t-$ ware before general release).

In addition to the Beta Test evaluation, a separate effort to validate ROCCID is underway. The objective of this validation effort is to use ROCCID to identify critical design and operating parameters that have a first order influence on combustion stability and performance, to evaluate combustor designs created by ROCCID, and to demonstrate through hot-fire testing the extent to which ROCCID can be used as an "a priori" predictive tool. Some general rules were established to evaluate the hardware design for validation. First, the selected design must have the capability of providing for both stable and unstable operation through changes in operating conditions (chamber pressure and/or mixture ratio) as predicted by ROCCID. Ideally, this change between stable and unstable operation should be achievable with and without acoustic damping devices. Second, the designs must be sufficiently different from designs tested previously so that a clear validation of ROCCID as an "a priori" predictive tool is achieved.

\section{ROCCID Methodology Overview}

ROCCID contains three main components:

(1) An Interactive Front End (IFE) that provides guidance to the user for input setup, input and output control, and the generation and maintenance of library files for replay, propellant properties, and combustion gas properties.

(2) A point analysis option that provides performance and combustion stability analysis of existing combustor designs.

(3) A point design option that creates the essential combustor design features for a high performance and stable rocket engine from specified design requi rements.

Both the point analysis and point design options use a library of performance and combustion analysis models that were selected from existing appropriate codes. These analysis models are contained within ROCCID in a modular format. This permits the user to access specific models for a specialized sub-analysis or to use two or more models that perform similar functions to define and resolve uncertainties in that particular area of the analysis. Modular construction al so permits easier and less costly upgrades to the methodology as new analys is models are developed.

The IFE is a menu driven preprocessor constructed using an extensive library of interactive subroutines. Each input character is checked in the IFE for validity. Warnings are displayed when input errors are sensed. Replay files that contain all case input are.created and maintained. These files can be edited and used as input for a subsequent session. The user may repeatedly alter the input until the desired result is achieved. Required propellant properties for both the injected fuel and oxidizer and their resulting combustion gas are internally generated and maintained in files.

Upon completion of the input deck, the user may execute either the point analysis or point design options. These options contain many interactive decision points for the user. Upon completion of an analysis or user termination, the run stream returns to the IFE to monitor the results, record, print pertinent information, and prepare input for the next run.

The performance of the combustor is defined by the energy release efficiency. This accounts for 
combustion efficiency limitations resulting from incomplete propellant vaporization and/or mixing. The energy release efficiency is calculated using the JANNAF simplified performance procedure ${ }^{3}$ and the propellant vaporization and mixing limitations from the steady state combustion analysis. An input file for use in the TDK/BLM performance analysis of the complete engine is also generated.

A steady state combustion analys is including propellant atomization, vaporization, and mixing supplies key input to the performance and stability analyses. Four models/correlations for propellant drop size are included for standard injector elements including showerhead, doublet and triplet impinging elements, and shear and swirl coaxial elewents, Drop sizes from all applicable correlations are calculated and displayed fōr compāíison. A user may select any of the calculated values for performance and stability analyses or provide another estimated value. Propellant vaporization is calculated using the generalized length correlation.2 Propellant mixing is based on the use of a unielement mixing efficiency value determined previously from cold flow measurements and adjusted for interelement mixing effects.

The combustion stability analysis can be made with a large array of models used to calculate the chamber admittance and the burning and injector response magnitudes. These models provide the capability to estimate combustion stability margin for all common types of combustor instabilities including chugging and chamber acoustic coupled (high frequency) modes. The effects of damping devices such as acoustic cavities and baffles are also considered by these models.

The design requirements for combustor cooling are established using techniques outside of ROCCID These requirements may include estimates of fuel film cooling required for chamber and baffle walls, dump cooling of baffle tips, and bulk temperature increases resulting from regenerative cooling of the nozzle, chamber, and resonator/baffle components. This information is used to calculate the propellant injection temperatures, injection orifice requirements, and the local flow injection mixture ratios.

ROCCID displays the stability analysis results in terms of the calculated growth coefficient $(\lambda)$ for the particular acoustic mode of concern. This growth coefficient represents the amount of amplification required by the chamber to achieve the condition where the driving required to support the waveform exactly equals the driving response present within the system. Thus a value of $\lambda=0$ represents a neutral stability condition, $\lambda>0$ represents an unstable condition, and $\lambda<0$ represents a stable operating condition.

The growth coefficient, in terms of the traditional combustion instability transfer function format, is illustrated in Fig. 1. Three typical situations are illustrated in this example. Figure 1(a) illustrates results of a traditional stability analysis where the shaded region formed by overlapped chamber response and combustion response curves indicate the potential for an instability. However, this traditional analysis does not include a survey of chamber admittances that would lead to a growth coefficient value which would provide zero stability margin, i.e., chamber response and combustion response curves being tangent at some point. The growth coefficient at this zero margin point provides a quantitative assessment of stability. Figures $1(\mathrm{~b})$ and (c) illustrate unstable and stable quantitative predictions, respectively, wherethe growth coefficient is used to define the relative stability based on the rate of pressure applitude growth $(\lambda>0)$ or decay $(\lambda<0)$. The following is the exponential relationship used to define $\lambda$ :

$$
A / A_{O}=e^{\lambda \Delta t}
$$

where $A / A_{0}$ is the pressure amplitude ratio change over the period, $\Delta t$ (sec).

The resultant growth coefficient can be related to the damp time required for dynamic stability as defined in CPIA 247, by defining a growth coefficient ( $\left.\lambda_{C P} / A 247\right)$ required to achieve a $10: 1$ overpressure damping within the damp time specified from CPIA 247. That is:

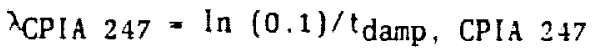

where

${ }^{t}$ damp, CPIA $247=1.250 / \sqrt{ } f(\mathrm{sec})$,

$f=$ frequency of the unstable oscillation

reducing

$$
\lambda_{\text {CPIA } 247=-1.842 \text { Vf } \quad(1 / \mathrm{sec})}
$$

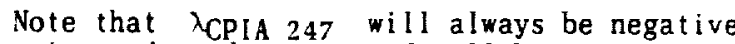
indicating a damped system and will be a function of the frequency (mode) of the damped oscillation. Therefore, if the growth coefficient is equal to or less than $\lambda$ CPIA 247 the system is dynamically stable. Conversely, if the growth coefficient is greater than $\lambda$ CPIA 247 the system is not dynamically stable.

\section{Validation Design Requirements}

The creation of a combustor design consists of an evolutionary process where design requirements and operational goals are used to establish design parameters for the injector and combustion chamber. Iterations to the set of critical design parameters are performed to meet performance goals while providing for stable combustion. ROCCID has been used to exanine the sensitivity and influence of several injector and combustor design parameters on the predicted combustor performance and combustion stability.

The propel lant combination of LOX/RP-1 has been selected for study using ROCCID and for eventual hot-fire testing to validate ROCCID capabilities. This propellant was selected because historically, it has proven to be a difficult propellant to provide both stable combustion and high performance.

Nominal design propellant injection temperatures of $1744^{\circ}{ }^{\circ}$ for liquid oxygen and ambient condition $\left(515^{\circ} \mathrm{R}\right)$ for RP-1 have been selected. These conditions represent normal propellant storage temperatures within the Aerojet test facility and therefore are the most cost effective test conditions. 
A nominal design mixture ratio of 2.8 has been selected since this approximates an optimum performance design from a thrust chamber performance viewpoint. Note that this mixture ratio value has been selected for design purposes only. The effects of mixture ratio variation on a fixed design have been evaluated using ROCCID and will be a key operating parameter for validation testing.

Thrust chamber size is a key design parameter, particularly from a combustion stability standpoint. The chamber diameter has a direct effect on the resonant frequency of acoustic modes within the chamber. Large chambers appropriate for booster engine application ( $\mathrm{DC}=17.5-44$ in.), have lower resonant frequencies that are more likely to couple with typical combustion responses. On the other hand, subscale chamber diameters of 5.5 and 7.68 in. have been successfully used in the past for combustion stability investigations. 4,5 For this study, a nominal baseline chamber diameter of $7.68 \mathrm{in}$. has been selected since it is a proven "subscale" design and residual hardware is available from the test program in $\operatorname{Ref} .5$.

A contraction ratio of $2: 1$ that corresponds to a throat diameter of $5.43 \mathrm{in}$. and a nominal design chamber pressure of 1250 psi were selected to provide a large operating chamber pressure variation within the existing hardware and test facility capabilities. The operational envelope of the validation hardware for the Aerojet E-4 test facility is shown in Fig. 2. A variation in mixture ratio from approximately 1 to 10 is possible at the nominal chamber pressure of 1250 psi. A maximum chamber pressure of approximately 1800 psi is possible at the nominal mixture ratio. The mixture ratio excursion range diminishes as chamber pressure is increased due to the facility run tank pressure limits.

Impinging injector designs were selected for this evaluation since they are most appropriate for liquid-liquid injection. Specifically, the like doublet and OFO triplet elements, both of which are included in ROCCID, were evaluated. The OFO triplet element was selected over the FOF since the propellant density and mixture ratio will result in equal orifice diameters with an OFO element but not with the Fof triplet. From experience, equal or if ice diameters are desirable with a triplet element to provide optimum mixing and atomization.

A summary of the selected design parameters for this study is presented in Table I. Design parameters from two recent combustion stability investigations in Refs. 4 and 5 , are also provided for comparison purposes.

\section{Downselect Criteria}

Criteria were established to select which injector to use to validate ROCCID. Because of limited resources, one and at best two different thrust chamber designs could be selected for design and testing. The criteria were established on the basis of providing the best test of the capabilities of ROCCID. The criteria are:

(1) Largest negative and positive growth coefficients for the most stable and unstable modes wi thout acoustic damping.
(2) Highest sensitivity of combustion stability to chamber pressure and mixture ratio.

(3) Greatest design change from existing data base

(4) Capable of stabilization at nominal operating conditions using an acoustic cavity.

(5) Highest confidence in modeling drop size and mixing efficiency.

(6) Ease of incorporating design features into existing hardware.

\section{Selection of the Injector}

Three injector designs, fine triplet, coarse triplet, and like-on-like doublet, were selected to be evaluated by ROCCID for detail design and testing. Initially, the point design option of ROCCID was used to size the injectors for the nominal operating conditions. Thereafter, the analys is portion of ROCCID was used to perform trade studies on the initial designs. The experience gained from the experimental results of Ref. 4 was also applied to the analysis. Also from past experience, certain model combinations in ROCCID were used because they produced good results. HIFI was used to analyze the chamber response. Smith-Reardon and $N / \tau$ correlations were used to analyze the burning response. IN] was used to analyze the injector response.

The injector orifice sizes evaluated were $0.090 \mathrm{in}$. For the fine triplet, $0.159 \mathrm{in}$. for the coarse triplet, and $0.100 \mathrm{in}$. LOX and $0.065 \mathrm{in}$. fuel for the like-on-like doublet. The predicted performance efficiencies for all three injectors were greater than 97 percent so performance did not become a critical concern in the selection process.

An extensive number of stability predictions were generated and only a portion will be discussed in the following section. References 6 and 7 should be examined for more details.

The chug stability of the three injectors was analyzed. The fine triplet and the doublet have low chug thresholds at about 300 psi. The coarse triplet has a more undesirable chug threshold at about 600 psi. Considering that the nominal operating pressure is 1250 psi, this higher chug pressure limit for the coarse triplet does not allow for much leeway in throttling the engine to find stable and unstable high frequency stability regions.

The high frequency stability characteristics of the three injectors were also analyzed. The coarse triplet was found to be the most stable injector design ( $\lambda$ less than -37 in all modes) without acoustic damping devices. From a flight hardware designer's point of view, this would be an excellent design. However, since our validation criteria require both 5 table and unstable operation for verification, the coarse triplet injector design is not sufficient for ROCCID validation. If resources are available, this design may turn out to be a good choice for a secondary, very stable, alternate test series to demonstrate ROCCIO's capability to stabilize the thrust chamber through injector design changes (i.e., combust ion response). 
The doublet was found to be stable except for the first tangential mode. The doublet looks very promising because it has a region of operation where it can be driven stable and unstable by changing the mixture ratio as shown in Fig. 3. The doublet can be stabilized using acoustic damping devices which will allow validation of the models for damping devices. The major drawback of the doublet is that it is very similar to the design used in Ref. 5. Since this is a validation of the predictive capability of the models in ROCCID, using an injector so close to the anchored hardware makes this injector a secondary choice.

The fine triplet design was found to be unstable in several different modes with varying operating conditions. Figures 4 to 7 show ROCCID predictions of stability changes over the operating map. The first longitudinal (1L) mode is stable until lower chamber pressures are reached. The first tangential (1T), second tangential (2T), and first radial (1R) modes are unstable over wide changes in operating conditions. The orifice diameter was changed from 0.09 to 0.10 in, to see what the effect of orifice diameter had on stability. It did not improve stability margin sufficiently to provide any significant advantages. Damping devices were found to be very effective in damping out the unstable modes. Also, this design is very different from the hardware described in Reference 5 in terms of number of elements and orifice sizes.

Table 2 provides a rating of the candidate injector designs. It is obvious that the fine triplet injector is the best choice to validate the models contained within ROCCID. The fine triplet injector stability is sensitive to chamber pressure and mixture ratio variations which will allow for testing the sensitivity and predictive capabilities of the models. The fine triplet injector is suff $i-$ ciently different from previously tested injectors to allow a true "a priori" prediction. As a result, this injector was selected as the test hardware.

\section{Growth Coefficient Uncertainty}

The sensitivity of the stability predictions (in terms of the growth coefficient) to the pressure interaction index, $N$, and sensitive time lag, $\tau$, were evaluated ove $r$ a range of $N$ and $\tau$ values. The ranges of $N$ and $\tau$ values were selected based on estimates from three sources.

(1) The empirical variations in these parameters shown in Refs. 8 and 9.

(2) The calculated variation resulting from different droplet combustion mixture ratios and gas temperatures using the CRP model.10

(3) Variations in $\tau$ based on an estimated 1 percent uncertainty in energy release efficiency and relating that uncertainty to a change in vaporization time lag.

The three techniques yielded similar results. Based on the Ref. 8 data the uncertainty in $N$ was estimated to be \pm 26 percent $(0.80 \pm 0.20)$ and the uncertainty for $\tau$ was +43 percent, -31 percent $\left(0.7 \times 10^{4} \text { sec to } 1.79 \times 10-4 \text { sec }\right)^{8}$ (Figs. $6(\mathrm{c})$ and $(d))$.

The CRP model was run for assumed fuel droplet surface mixture ratios of 0.7 to 2.4 and gas temper atures of 2500 to $6500{ }^{\circ} \mathrm{R}$ at the droplet surface These analyses resulted in $N$ values of 0.45 to 1.0 and $\tau$ values of $0.94 \times 10^{-4} \mathrm{sec}$ to $2.5 \times 10-4 \mathrm{sec}$, similar to the ranges shown from Ref, 8 but slightly larger.

Assuming a 1 percent performance uncertainty $(98+1$ percent) caused by a fuel droplet size uncertainty would yield a $\tau$ uncertainty of approximately 20 percent, again in the general range observed from the Smith-Reardon data.

The ROCCID model was run with the above variations in $N$ and $\tau$ from/Smith-Reardon at the nominal chamber pressure and mixture ratio $\left(\mathrm{P}_{\mathrm{C}}=1250 \mathrm{psi}\right.$, $0 / F=2.8)$. The results, as shown in Fig. 8 indicate large variations in predicted growth coef $\mathrm{i}$ cient, up to approximately $\pm 600 \mathrm{sec}^{-1}$ for the $2 \mathrm{~T}$ mode if both $N$ and $t$ variations are considered. However, implicit within ROCCID is a variation in $\tau$ due to engine operating conditions. Therefore, the data scatter leading to uncertainties in $\tau$ from Refs. 8 and 9 may be due to differences in the operating condition of the engines being evaluated. If only the uncertainty in $N$ is considered, the growth coef $f$ icient variations are reduced to $+25 \mathrm{sec}^{-1}$ for the $1 \mathrm{~L}$ mode, $+350 \mathrm{sec}^{-1}$ for the $1 \mathrm{~T}$ mode, and $+500 \mathrm{sec}^{-1}$ for the $2 \mathrm{~T}$ mode. Based on the statistical scatter in the existing empirical correlations of $N$ and the present state of the models, these large bands of uncertainty associated with the predictions are expected.

It should be noted that there is not an equal expectation of $N$ values within the published uncertainty band of \pm 26 percent. The nominal value is the most likely with the extremes, \pm 26 percent, probably representing a $\pm 3 \sigma$ standard deviation. If this is the case, then a statistical analysis of experimental data going into ROCCID could be performed to estimate the confidence level of the ROCCID predictions for calculated values of growth coefficient. A more detailed analytical and statistical evaluation of the data is recommended to allow a better understanding of the reasons for and consequences of the uncertainties in $N$ and $\tau$.

\section{Validation Testing}

Test planning is proceeding at this time Three test points without damping devices have been determined. Looking at Figs. 4 to 7 , one can see that at chamber pressure/mixture ratio combinations of $625 \mathrm{psi} / 7.50,1250 \mathrm{psi} / 1.15$, and $1250 \mathrm{psi} / 7.50$ stability should be achieved in all modes. These points will be tested to determine the model's capability of predicting undamped stable points. Several of the other points shown in Figs. 4 to 7 will be tested both with and without damping devices to determine the effectiveness of the damping device and predictive capability of the models.

\section{Conclusions}

It is evident from the extent of trade studies performed in a very brief period that ROCCID is a powerful tool. The ease with which an engine designer can make and analyze changes can potentially save many manhours. ROCCID is valuable because it documents how the designer arrived at a particular design. In the future, validation of the models in ROCCID can lead to upgrading insufficient models and determining the better analysis models. From this 
analysis, it is evident that the band of uncertainty associated with the models that industry relies on to design flight hardware is too broad and requires further study. The planned test program based on the trade studies will determine the "a priori" predictive capabilities of the models.

\section{References}

1. Pieper, J.L. and Muss, J.A., "Development of a Combustor Analytical Rocket Engine Analytical Design Methodology for Liquid Rocket Engines," Presented at the 26 th JANNAF Combustion Meeting, Jet Propulsion Laboratory, Pasadena, CA, Oct 1989 .

2. Priem, R.J., and Heidmann, M.F. , "Propellant Vaporization as a Design Criterion for Rocket Engine Combustion Chambers," NASA TR-R-67, 1960.

3. "JanNaF Rocket Engine Performance Prediction and Evaluation Manual," CPIA Publication 246, Apr . 1975 .

4. Jensen, R.J.., Dodson, H.C., and Claflin, S.E., "LOX/Hydrocarbon NASA Lewis Combustion Instability Investigation," NASA CR-182249, 1989 .
5. Muss, J.A., and Pieper, J.L., "Performance and Stability Characterization of LOX/Hydrocarbon Injectors," AIAA paper 88-3133. July 1988.

6. Pieper, J.L., "LoX/Hydrocarbon Rocket Engine Analytical Design Methodology Development and Validation: Application of the Analytical Design Methodology," NAS3-25556 Task 3.0 Report, Mar. 1990.

7. Pieper, J.L., and Walker, R.E., "LOX/Hydrocarbon Rocket Engine Analytical Design Methodology Development and Validation: ROCCID Validation Test Plan Development," NAS3-25556 Task 4.0 Report, June 1990.

8. Harrje, D.T., "Liquid Propellant Rocket Combustion Instability, NASA SP-194, 1972

9. Smith, A L.; and Reardon, F.H., "The Sensitive Combustion Time Lag Theory and Its Application to Liquid Rocket Combustion Instability Problems," Vol. I Engineer's Manual, Technical Report AFRPL-TR-314, 1968.

10. Nguyen, T.V., "Combustion Responses Yodel," Aerojet Engineering Analys is Report 9980:1998, July 1987.

TABLE 1. - COMPARISON OF SELECTED NOMINAL DESIGN PARAMETERS

\begin{tabular}{|c|c|c|c|}
\hline \multicolumn{4}{|c|}{ Combustion stability investigation } \\
\hline & NAS $3-25556^{a}$ & $\mathrm{~F} 04611-85-\mathrm{C}-0100^{\mathrm{b}}$ & NAS $3-2+612^{C}$ \\
\hline Propellant combination & $\mathrm{LOX} / \mathrm{RP}-1$ & LOX/RP-1 & $\mathrm{LOX} / \mathrm{CH}_{4}$ \\
\hline Mixture ratio & $2.8=\mathrm{TBD}$ & $2.9 \pm 0.3$ & $3.5 \begin{array}{l}-1.6 \\
+0.2\end{array}$ \\
\hline $\begin{array}{l}\text { Injection temperature } \\
\text { LoX }{ }^{\circ} \mathrm{R} \\
\text { Fuel }{ }^{\circ} \mathrm{R}\end{array}$ & $\begin{array}{l}174 \\
515\end{array}$ & $\begin{array}{r}174 \\
530 \pm 20\end{array}$ & $\begin{array}{r}174 \\
530 \text { to } 438\end{array}$ \\
\hline Chamber pressure, psia & $1250 \pm \mathrm{TBD}$ & $2000 \begin{array}{r}+100 \\
-1300\end{array}$ & $2000 \begin{array}{l}+100 \\
-500\end{array}$ \\
\hline Chamber diameter, in. & 7.68 & 7.68 & 5.66 \\
\hline Throat diameter, in. & 5.43 & 4.43 & 3.31 \\
\hline Contraction ratio & $2: 1$ & $3: 1$ & $2.92: 1$ \\
\hline Chamber length, in. & TBD & $8.5,13,20$ & 14 \\
\hline $\begin{array}{l}\text { Nominal thrust level, } \\
\text { lbf }\end{array}$ & 48000 & 57000 & 30000 \\
\hline $\begin{array}{l}\text { Total flowrate } \\
\text { lbm/sec }\end{array}$ & $150 \pm T B D$ & $180 \begin{array}{r}+10 \\
-90\end{array}$ & $190_{-15}^{+7}$ \\
\hline Injection element type & $\begin{array}{l}\text { OFo triplet } \\
\text { like doublet }\end{array}$ & $\begin{array}{l}\text { OFo triplet } \\
\text { like doublet }\end{array}$ & Shear coaxial \\
\hline
\end{tabular}

aLOX/Hydrocarbon Rocket Engine Analytical Design Methodology Development and Validation

boxygen/Hydrocarbon Injector Characterization 5

GLOX/Hydrocarbon Combustion Instability Investigation 4 
TABLE 2. - INJECTORS COMPARED ACAINST RATING CRITERIA

\begin{tabular}{|c|c|c|c|}
\hline \multirow[t]{2}{*}{ Rating Criteria } & \multicolumn{3}{|c|}{ Injector configuration } \\
\hline & $\begin{array}{l}\text { Fine ofo } \\
\text { triplet }\end{array}$ & $\begin{array}{l}\text { Coarse OFO } \\
\text { triplet }\end{array}$ & $\begin{array}{l}\text { Like-on-like; } \\
\text { one doublet }\end{array}$ \\
\hline $\begin{array}{l}\text { Largest negative and positive } \\
\text { growth coefficients for least } \\
\text { damped mode without acoustic } \\
\text { damping }\end{array}$ & Uost ustabte & $M 0 s t s t a b l e$ & Unstable \\
\hline $\begin{array}{l}\text { Best sensitivity of combustion } \\
\text { stability to } P_{C} \text { and } 0 / F\end{array}$ & 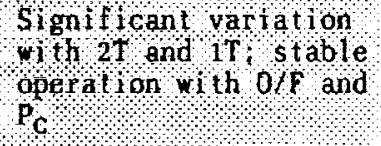 & $\begin{array}{l}\text { Much wilder } \\
\text { variation in } P_{C} \\
\text { and } 0 / F \text { required } \\
\text { to drive unstable }\end{array}$ & 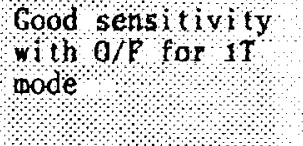 \\
\hline $\begin{array}{l}\text { Greatest change from existing } \\
\text { data base }\end{array}$ & 1c, $19,10,105,0$, & $\mathrm{N}_{0}, 0,125,10,0,159$ & $\begin{array}{l}\mathrm{N}_{\varepsilon}, 105 \text { to } 123 \\
\mathrm{D}_{\mathrm{o}}, 0.059 \text { to } 0.065\end{array}$ \\
\hline $\begin{array}{l}\text { Capable of stabilization at } \\
\text { nominal operating conditions } \\
\text { using an acoustic cavity }\end{array}$ & 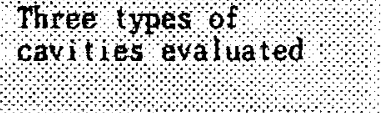 & $\begin{array}{l}\text { Stable without an } \\
\text { acoustic cavity }\end{array}$ & 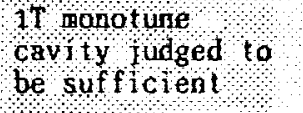 \\
\hline $\begin{array}{l}\text { Best confidence in modeling } \\
\text { drop size and nixing } \\
\text { efficiency }\end{array}$ & 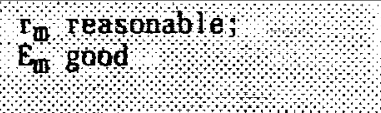 & $t_{\mathrm{p}} \mathrm{reasonabl}$ & $\begin{array}{l}\Gamma_{\mathrm{m}} \text { reasonable; } \\
\mathrm{E}_{\mathrm{m}} \text { reasonable }\end{array}$ \\
\hline $\begin{array}{l}\text { Ease of incorporating design } \\
\text { features into existing hard- } \\
\text { ware }\end{array}$ & 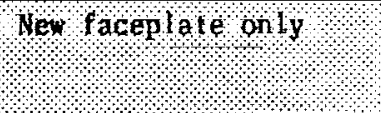 & $\begin{array}{l}\text { New faceplate and } \\
\text { injector core }\end{array}$ & $\begin{array}{l}\text { New faceplate and } \\
\text { injector core }\end{array}$ \\
\hline Preferred rating & 6 of 6 & 3 of 6 & 2 of 6 \\
\hline
\end{tabular}

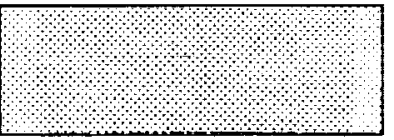

Indicates prefered characteristic 


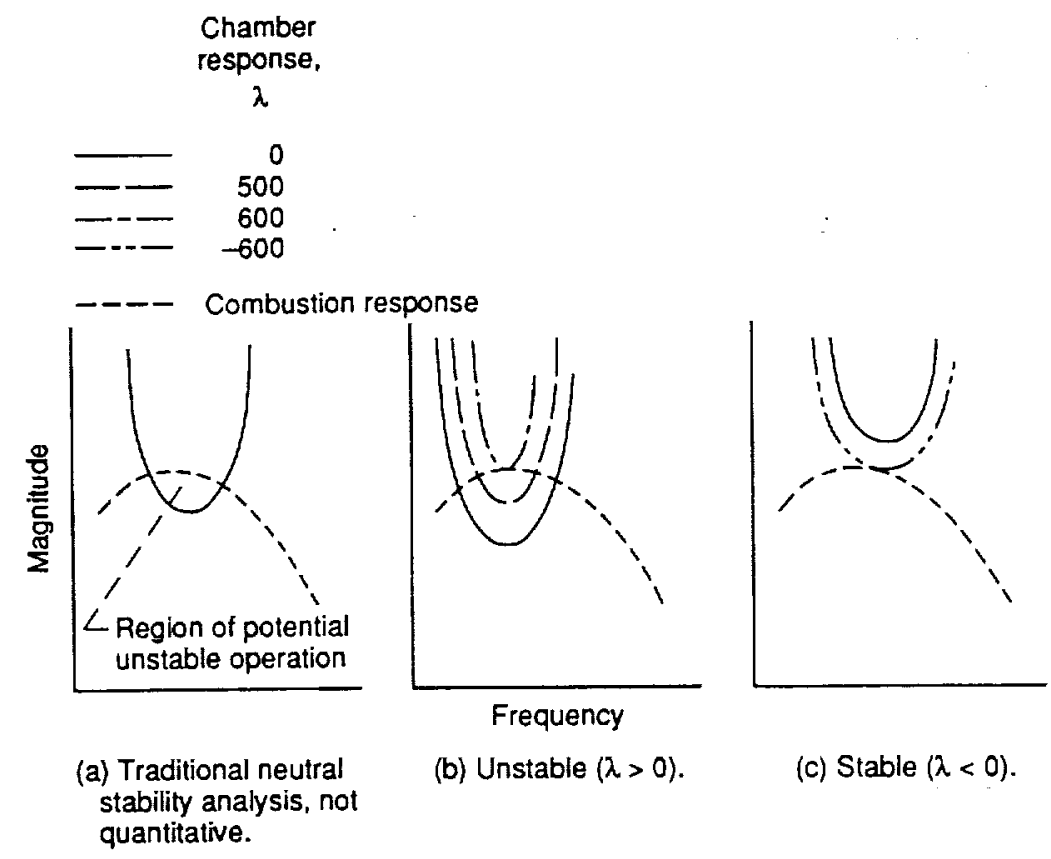

Fig. 1.- -llustration of the growth coefficient $\lambda$ in terms of traditional combustion stability transfer function format.

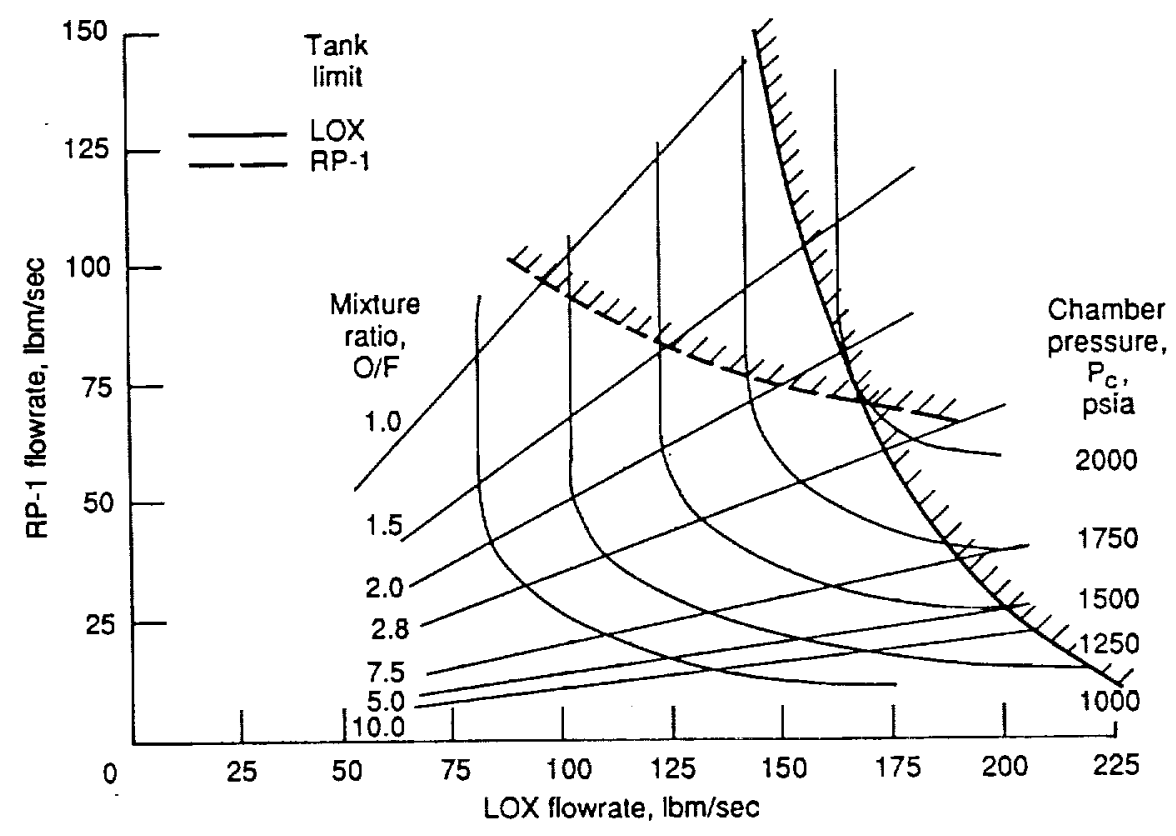

Fig. 2.-Facility operating limitations. 
CPIA 247

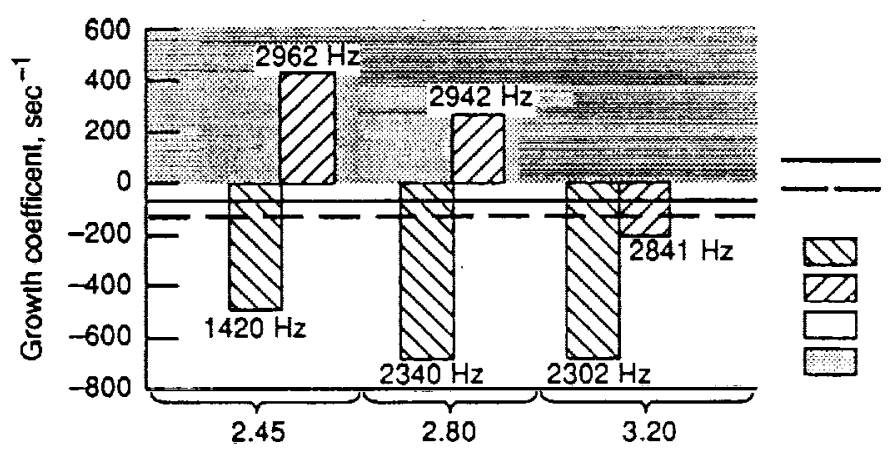

growth coefficient,

$\lambda_{\text {CPIA } 247}$,

$\sec ^{-1}$

$1 L(-72)$

1T $(-105)$

$1 \mathrm{~L}$ mode

1T mode

Stable region

Unstable region

Fig. 3.-Like doublet injector stability prediction, chamber pressure $=1250$ psia; length $=17$ in.; no damping.

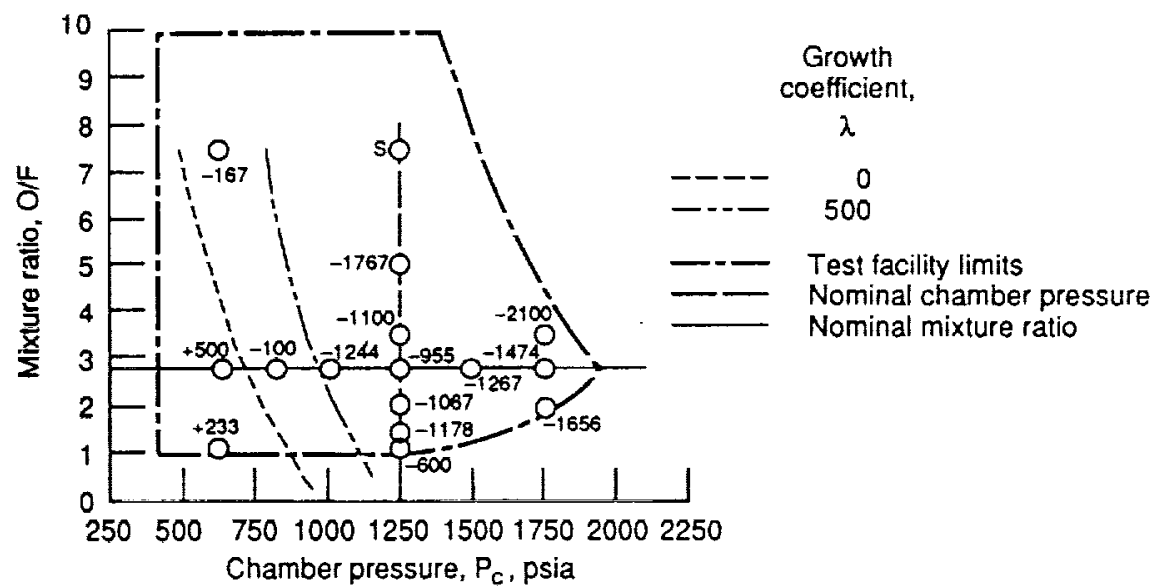

Fig. 4.-Fine triplet $1 L$ mode stability map showing values of $\lambda$ at various points as well as point predicted to be extremely stable (S).

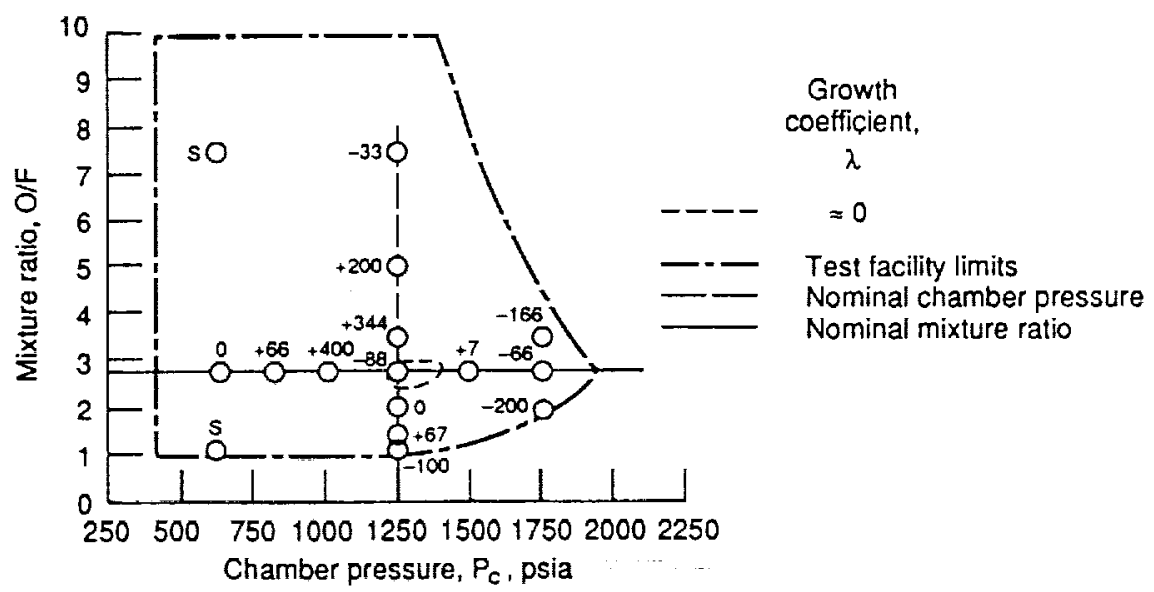

Fig. 5.-Fine triplet 1T mode stability map showing values of $\lambda$ at various points as well as points predicted to be extremely stable (S). 


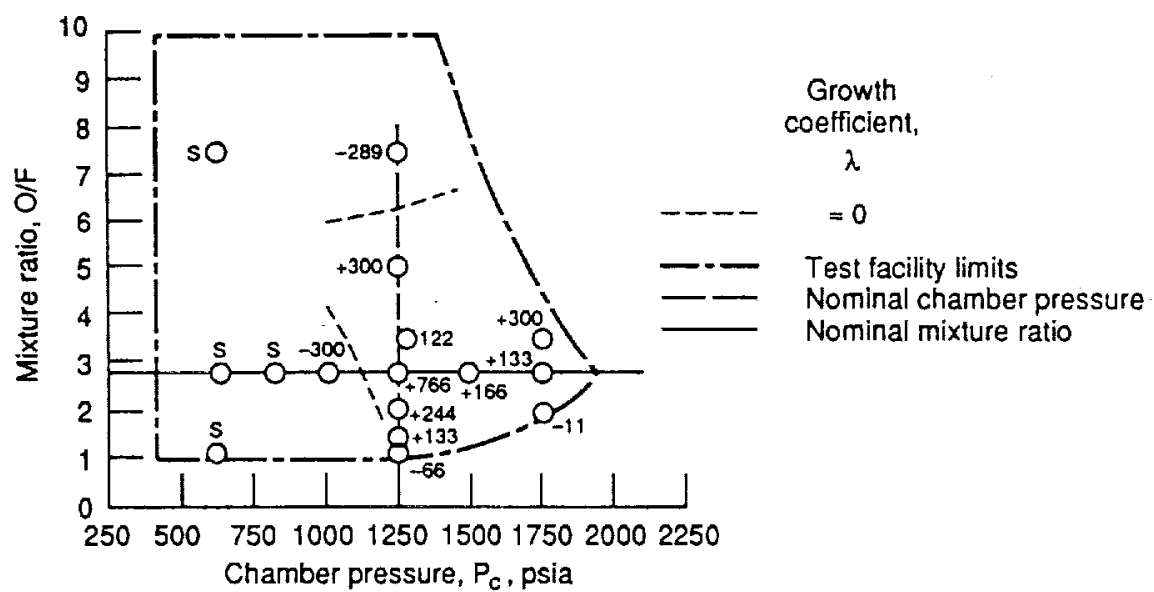

Fig.6.-Fine triplet $2 T$ mode stability map showing values of $\lambda$ at various points as well as points predicted to be extremely stable (S).

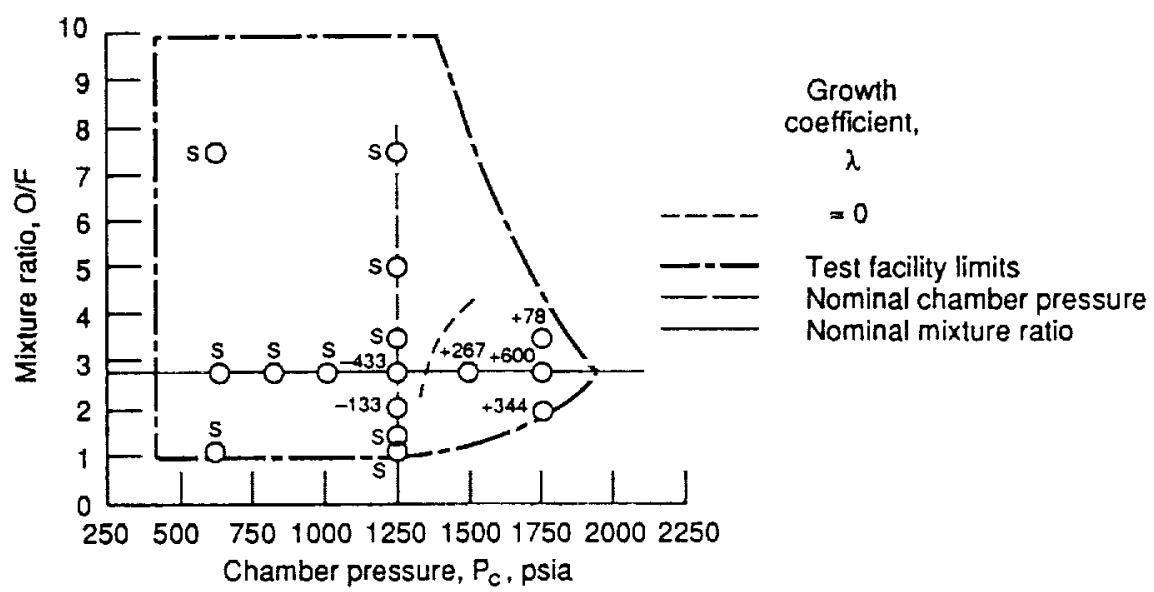

Fig. 7. Fine triplet 18 mode stability map showing values of $\lambda$ at various points as well as points predicted to be extremely stable (S).

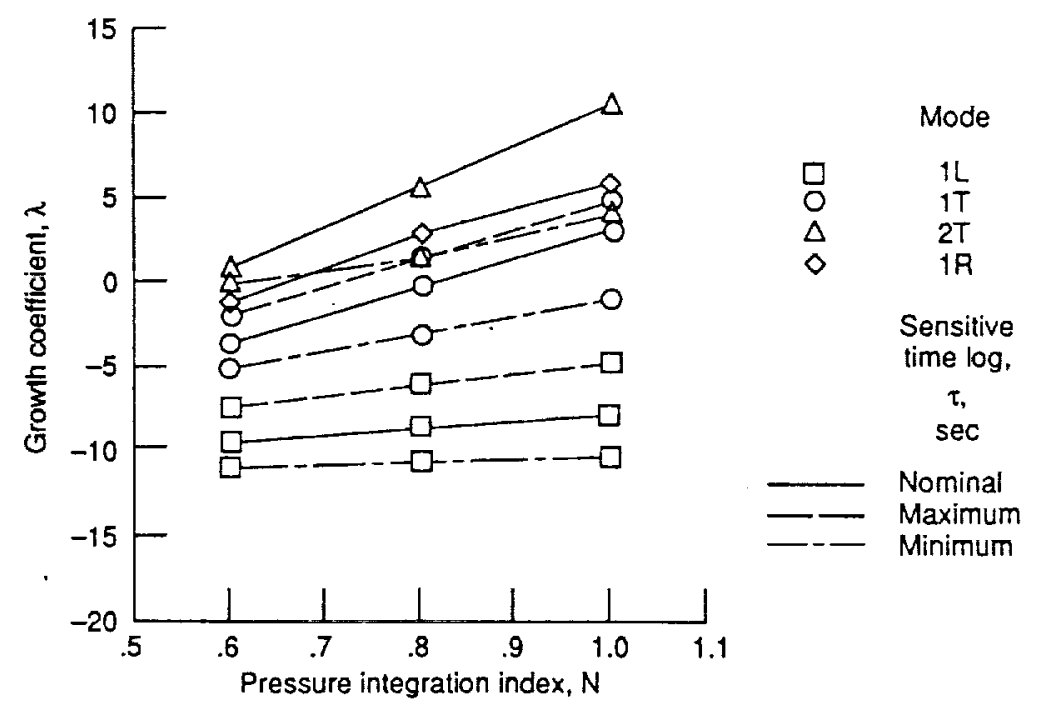

Fig. 8. -Variation of growth coefficient $\lambda$ with $N$ and $\tau$. 


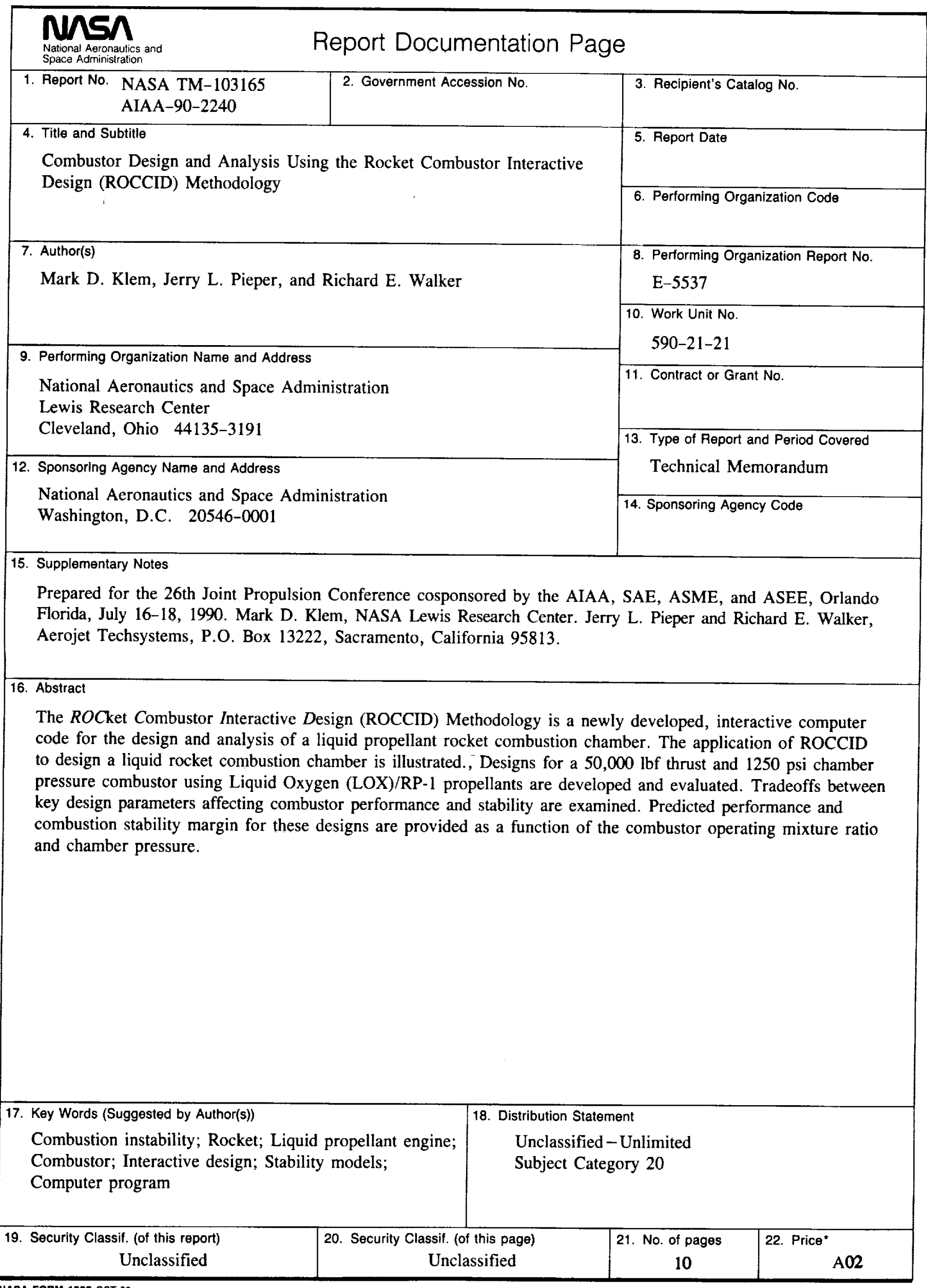

